\title{
Method for the Production of Fat from Raw Materials and Animal Waste
}

\author{
Ruslan Maratbekovich Iskakov ${ }^{1}$ (D) Assel Maratbekovna Iskakova², \\ Murat Zhusypbekovich Nurushev ${ }^{3}$, Altyngul Kumashevna Khaimuldinova ${ }^{4}$ \\ and Nurlan Kazhkenovich Karbayev ${ }^{4}$
}

${ }^{1}$ Department of Agrarian Technique and Technology, S.Seifullin Kazakh Agro Technical University, a 62 Prospect Pobedy, Nur-Sultan, 010000, Republic of Kazakhstan.

${ }^{2}$ Department of Public Health, Semey State Medical University, 103 Abay Street, Semey, 071410, Republic of Kazakhstan.

${ }^{3}$ Department of Ecology, Eurasian National University named after L.N. Gumilyov,

2 Satpayev Street, Nur-Sultan, 010000, Republic of Kazakhstan.

${ }^{4}$ Department of Standartization and Certification, Eurasian National University named after

L.N. Gumilyov, 2 Satpayev Street, Nur-Sultan, 010000, Republic of Kazakhstan.

\begin{abstract}
The aim of this article was to study degreasing of raw materials raw fish bone waste and animal waste. A new method was developed, aimed at intensive extraction of fat with an additional absorber- delimonene, placed in water during high-temperature cooking of raw materials of animal origin. Delimonene is a widespread terpene hydrocarbon, and a primary component of orange peel oil (constitutes

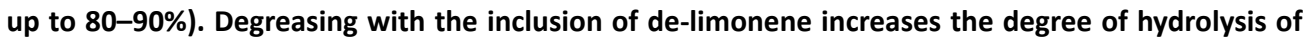
collagen from animal raw materials, which intensifies the extraction of fat from the processed raw materials. High-temperature cooking promotes the breakdown of triglycerides into free fatty acids, which further break down into low molecular weight products. At the end of the heat the temperature of the heating plates is $70-90^{\circ} \mathrm{C}$, the pressure inside the boiler is $1.6,-2.4 \mathrm{kPa}$, the duration is $60-100$ minutes treatment of the raw material, a two-phase system was obtained: dry fat greaves and fat. Fat was sucked off by pumps connected to digesters, and greasy greaves were sent for degreasing by pressing. The method produced broth, fat, and feed.
\end{abstract}

Keywords: degreasing, fat, animal waste, cooking, de-limonene

*Correspondence: rus.iskakov79@mail.ru

(Received: November 05, 2020; accepted: April 25, 2021)

Citation: Iskakov RM, Iskakova AM, Nurushev MZ, Khaimuldinova AK, Karbayev NK. Method for the Production of Fat from Raw Materials and Animal Waste. J Pure Appl Microbiol. 2021;15(2):716-724. doi: 10.22207/JPAM.15.2.23

(C) The Author(s) 2021. Open Access. This article is distributed under the terms of the Creative Commons Attribution 4.0 International License which permits unrestricted use, sharing, distribution, and reproduction in any medium, provided you give appropriate credit to the original author(s) and the source, provide a link to the Creative Commons license, and indicate if changes were made. 


\section{INTRODUCTION}

When processing raw materials of animal origin, including those of waste fish, for the production of feed products, ${ }^{1,2}$ it is important to create conditions for the not allowing this waste to be consumed by the population, and to guarantee food security to the population and human health ${ }^{3-4}$. At the same time, attention should be paid to non-waste complex processing of raw materials with the aim to obtain the maximum possible number of useful and safe products $^{5-9}$. When processing raw materials of animal origin, their degreasing is required. In this case, cooking raw materials of animal origin is of great importance. This is carried out to destroy the structure of tissues and weaken the bonds between protein and fat cells. When bound mass is easily separated from the bones, the end of the cooking process is reached. At the same time, the topical issue is the provision of effective technologies as well as new and efficient equipment, which contribute to the large-scale production of high-quality fat. Therefore, the improvement of technology and techniques for defatting raw materials of animal origin aimed at obtaining valuable fat is an urgent topic for research.

\section{MATERIAL AND METHODS}

The research materials included: devices for degreasing raw materials of animal origin, in particular, fish and bone raw materials, marine mammals, invertebrates, fish, waste of fish bones (tail fins, scales, fish bones, and fish heads), and ready-made fat.

One of the methods for studying the complex, multidimensional, and interrelated processes as well as the physical and chemical phenomena (such as the laws of heat and mass transfer), which occur during the process of degreasing, is a system analysis. It was conducted according to the methodology of mathematical modeling of technological processes developed by the school of V.V. Kafarov ${ }^{10}$. This hierarchical structure of system analysis includes five levels ${ }^{10}$.

Degreasing studies were carried out in a digester (KZh brand, Russia). During the study, a control damper was installed in the lower part of the inlet hopper to regulate the feedstock supply. A stopwatch was used to measure the time, with accuracy class of $\pm 1 \mathrm{~s}$. To measure the consumption of electrical energy, a three-phase multi-limit electric meter of the SAZU type, with accuracy class of 2.0 was used. A kilowatt meter was used to measure the power, with accuracy class of $1.5 \%$. To measure the pressure in the device for degreasing, a pressure measuring transducer "AIR-20" was used, which is equipped with an RS232 interface for communication with a computer. The research was carried out in the Zaysan farm of the East Kazakhstan region.

The determination of the fat content was carried out using the Reutov method ${ }^{11}$, as follows: the crushed raw material was dried in drying cabinet SNOL within 30 minutes, placed in a special sleeve, (which is a cylinder made of cotton), and weighed - starting with an empty sleeve and subsequently with a filled one. After weighing, the sleeve was installed in the extraction apparatus, (Soxhlet extractor (Soxhlet apparatus) is a device for continuous extraction of hardly soluble solids from solid materials) and the mass in the sleeve was treated with a solvent (Diethyl ether is one of the most widely used solvents in laboratory practice. It has good dissolving power and at the same time low boiling point. An ester in which the four hydroxyl groups of pentaerythritol are esterified with synthetic fatty acids with different lengths of the hydrocarbon radical), which slowly entered the sleeve. The extraction is carried out until the drops of ether coming out of the sleeve remain on the glass. . After extraction, the mass was removed from the sleeve, dried, and cooled. The fat content $(X$, in \%) was determined by the formula:

$$
X=m_{2}-m_{1} / m
$$

where $m_{2}$ is the mass of the container with the dried sample before extraction, $\mathrm{gm}_{1}$ is the weight of the container with the dried sample after extraction, gm is the weight of the sample, $g$

\section{RESULTS}

A method to produce fat and feed meal from waste raw materials of farm animals and a compact line for its implementation have been developed. The originality of the method is 
confirmed by our utility model patent (No. 4850), issued by the National Institute of Intellectual Property of the Ministry of Justice of the Republic of Kazakhstan ${ }^{12}$.

The technical result is a method for the production of fat and feed meal of high biological value from raw materials of animal origin as well as is a compact, easily mobile line for the production of fat and feed meal using small, simple technological equipment of high reliability and performance. This equipment provides a largescale and high production of fat and feed meal of high biological value.

This is achieved because of the fact that in the known method for the production of feed and a line for its implementation, including a power grinder installed during the technological process, digesters equipped with impulse pumps for sucking out fat, a container for collecting fat, a drainage device, devices for drying and grinding, a hopper for the finished product, it is proposed to additionally include a saw for sawing in order to ensure reliable and uniform processing of raw materials of various sizes. The technological processes of drying and fine grinding should be carried out in separate devices in order to achieve a high operability of the device for grinding raw materials using hammers and discs with rods, contributing to additional splitting of raw materials. In order to ensure highly efficient fine grinding of raw materials, preliminary vortex drying of raw materials in a drying device should be carried out, which guarantees the production of feed flour of high biological value. Due to high-temperature convective dehydration, fat production should be carried out in digesters with the inclusion of an additional component in the cooking process- de-limonene, in order to intensify the extraction of fat from raw materials.

Figure 1 shows a line for the production of fat and feed meal from raw materials and animal waste. The method is carried as follows: raw materials of animal origin are fed to a saw for sawing [1]. They are then fed into a power grinder [2], where the raw material is pre-crushed by working elements by shock-cutting in sections. Working elements - rotating knives with cutting edges that form a discontinuous helical line. Made of stainless steel. The cutting edge in each sector is made according to a logarithmic curve with a generatrix angle equal to the coefficient of friction of fish bone raw materials against

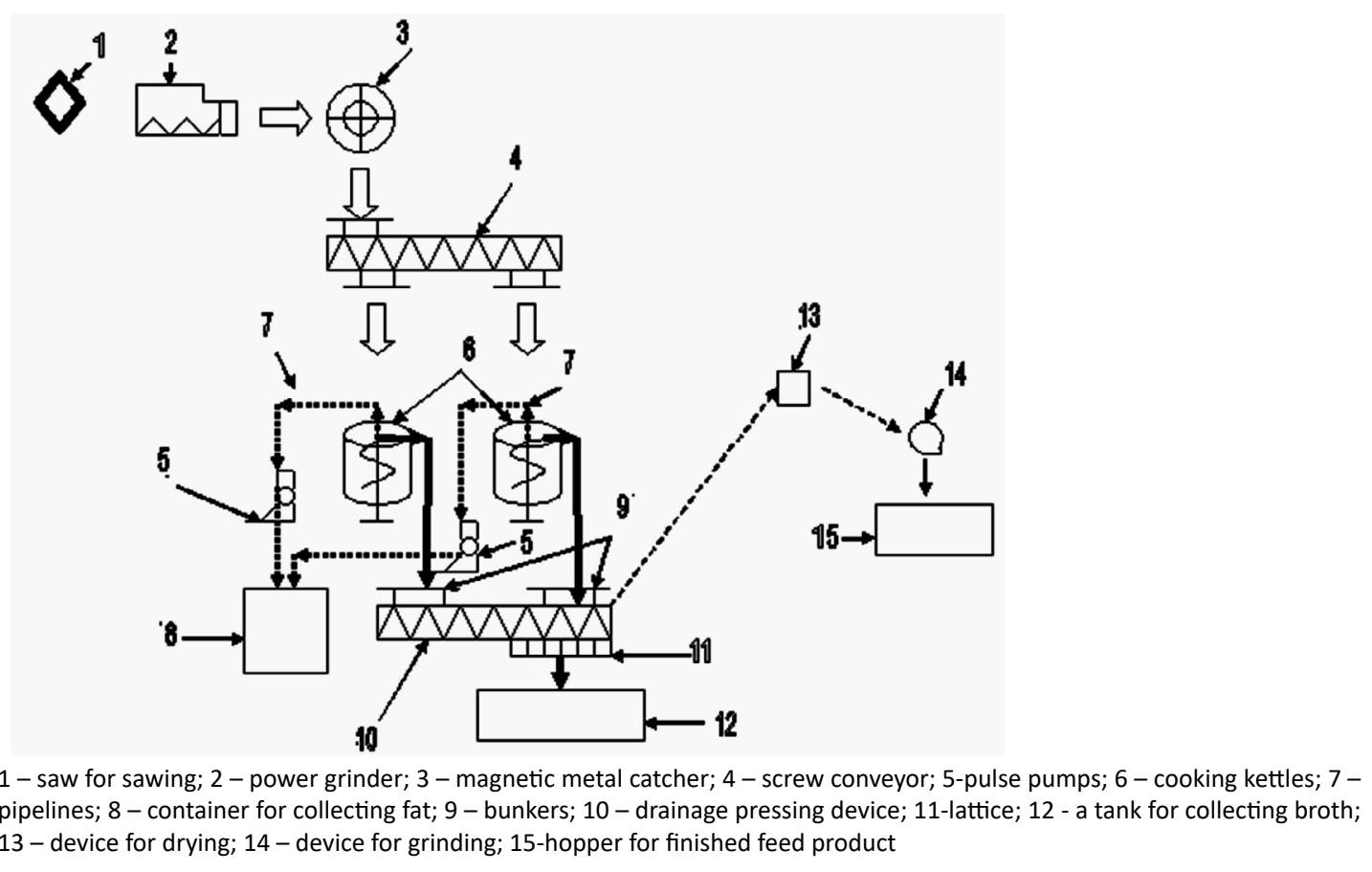

Fig. 1. Line for the production of fat and feed meal from raw materials and animal waste 
steel, and the electric motor is kinematically connected to the intermediate shaft of the flywheel through a V-belt transmission, the gear of which interacts with the gear wheel of the grinder shaft. They are then run through a magnetic metal catcher [3] and further along a screw conveyor [4]. The raw material then enters the digesters [5], where it is boiled and degreased. Later, de-

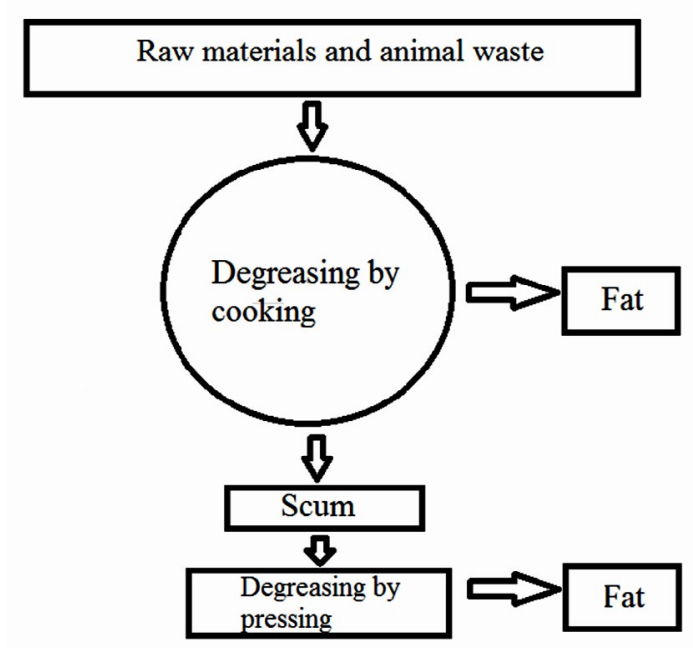

Fig. 2. Technology for degreasing raw materials and animal waste limonene is added to the digesters with the help of impulse pumps [6]. Fat is sucked out by the digesters [6], through the pipeline [7] into the container [8] which collects this fat. Subsequently, the defatted, wet raw material from the digesters ${ }^{6}$ enters through the bins [9] into the drainage press device [10], where through the grate [11], the broth is drained into the broth collection tank [12]. Thereafter, the defatted, wet raw material enters the device for drying [13], where convective hightemperature dehydration of the raw material takes place with a stream of hot air. This defatted and dried raw material enters the device for grinding [14], where it is finely crushed using rotating pier pads and discs with rods. The crushed product enters the hopper [15], to give the finished feed product. Working elements - rotating knives with cutting edges that form a discontinuous helical line. Made of stainless steel. The cutting edge in each sector is made according to a logarithmic curve with a generatrix angle equal to the coefficient of friction of fish bone raw materials against steel, and the electric motor is kinematically connected to the intermediate shaft of the flywheel through a V-belt transmission, the gear of which interacts with the gear wheel of the grinder shaft.In order to study the process of degreasing, a novel

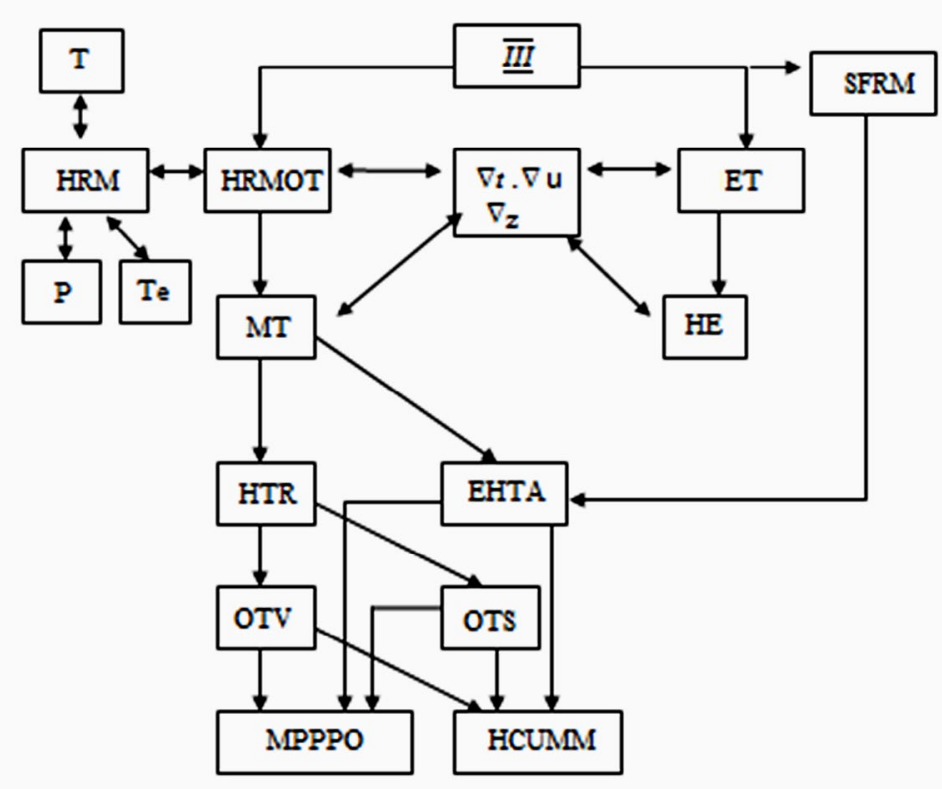

Fig. 3. Block diagram of physical and chemical effects (III) the hierarchy level of the system analysis of the process of degreasing raw materials and animal waste 
technology has been developed (Figure 2). The raw materials were loaded into the digester with the stirrer running. The process of loading the

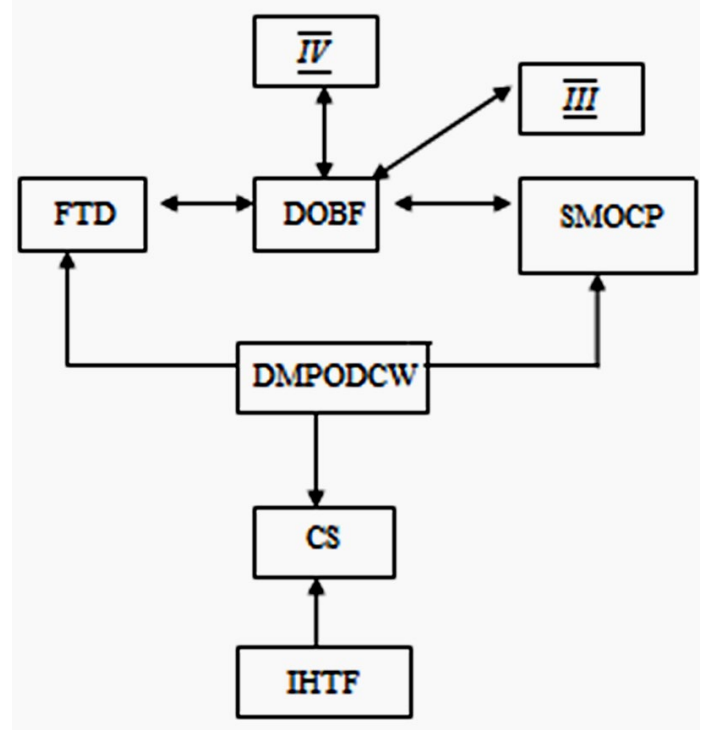

Fig. 4. Block diagram of the hierarchy level of the system analysis of the degreasing process of raw materials of animal origin raw material into the digester began with loading the fish bone raw material, which prevented the mass from burning and the formation of a crust on the inner surface of the boiler. After loading the subsequent fish and bone raw materials, water was poured into the digester to cover this raw material, and de-limonene was added. The lid was closed. Live steam was used as a heat carrier and was generated in an electric heater and fed into the cavity between the double walls of the digester. Heating of the raw material in this method was carried out without contact with the heat carrier and only through the heated wall of the digester. The air-vapor mixture was removed with a vacuum pump. At the end of the heat treatment of the raw material, a two-phase system was obtained: dry fat greaves and fat. The fat was sucked off by pumps, and greasy greaves were sent to degreasing by pressing.

\section{DISCUSSIONS}

The main component in identifying the primary factors affecting the degreasing process of raw materials of animal origin are the third (III), fourth (IV), and fifth (V) levels of the hierarchical

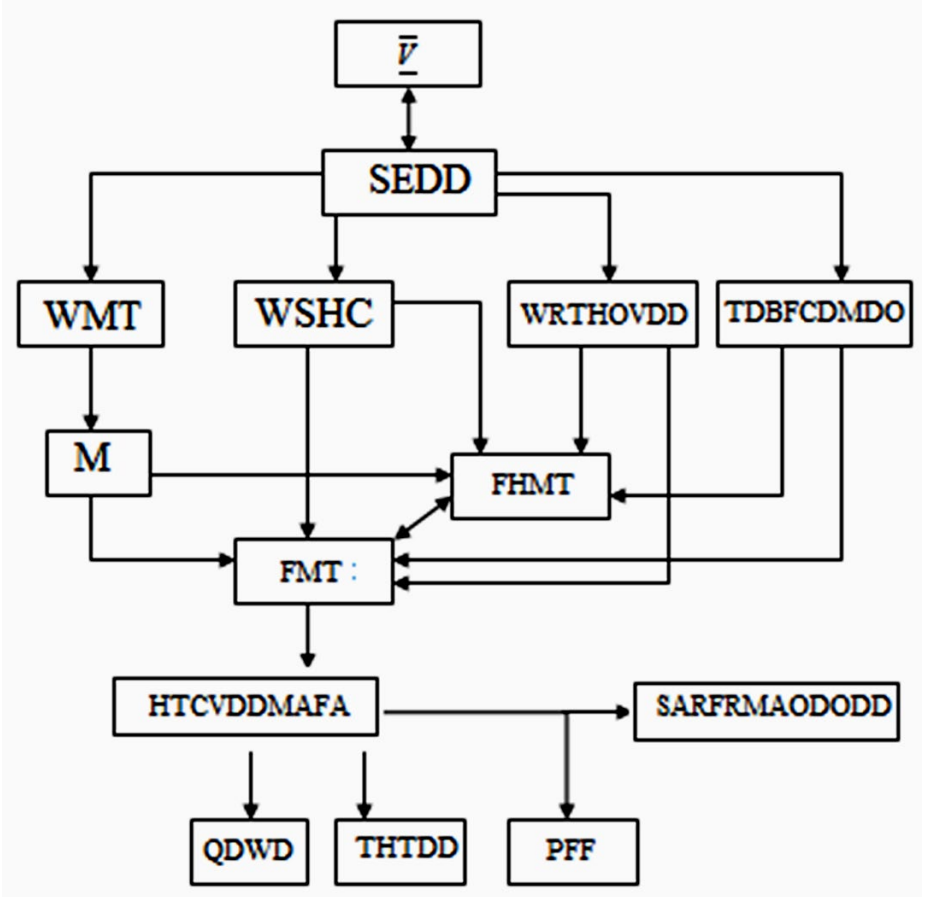

Fig. 5. Block diagram (V) of the hierarchy level of the system analysis of the degreasing process of raw materials of animal origin 
structure of the system analysis. The (III) level of the hierarchy of the system analysis includes physicochemical phenomena, the structural diagram of which is illustrated in Figure 3.

The internal structure of degreased fatfree raw materials depends on their moisture and fat contents. As a result of degreasing, in the object of processing, two effects are revealed: heating of the raw material to the optimal temperature (HRMOT), and holding of the raw material (HRM) at a certain time (T), pressure (P), and temperature (Te), mass transfer (MT), energy transfer (ET) - heat exchange (HE), and separation of fat from raw materials (SFRM). Energy transfer is a process during which substances with a complex structure are split into simpler ones or oxidized, which is characteristic of raw materials of animal origin. Heat exchange is a spontaneous irreversible transfer of heat (more precisely, energy in the form

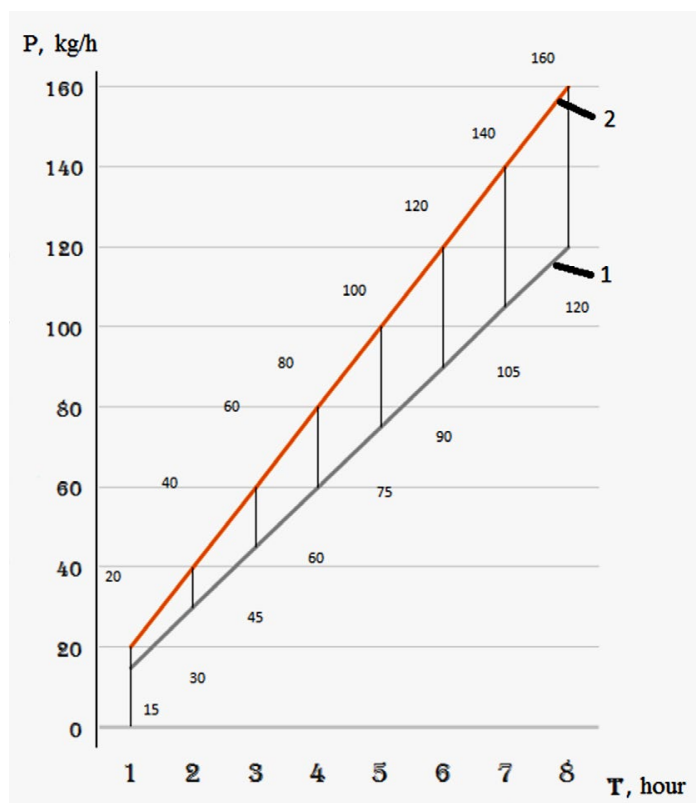

Fig. 6. Dependence of degreasing performance on time of heat) between bodies or areas inside the body with different temperatures. Therefore, the effects of energy exchange and heat transfer should be considered separately.

During the movement of heat, the gradients of temperature $\left(\nabla_{T}\right)$, moisture content (u), and fat content $\left({ }_{z}\right)$ are dominant. The discrepancy between the amount of heat moving from the body surface and the amount of heat coming from the inner layers leads to the appearance of heat transfer regions (HTR) in the volume (OTV) and over the surface (OTS), the expansion of heat transfer areas (EHTA), and the SFRM. Based on this movement, the physicochemical properties of the processing object (MPPPO) and the heat content of a unit mass of matter (HCUMM) change. Moreover, they are observed in each phase of the system, that is, they change both in water (broth-liquid phase) and in fish and bone raw materials (solid phase). The joint action of the two phases determines the mechanism of the degreasing process. The kinetics and dynamics of this process is described by the natural process of energy and mass transfer,

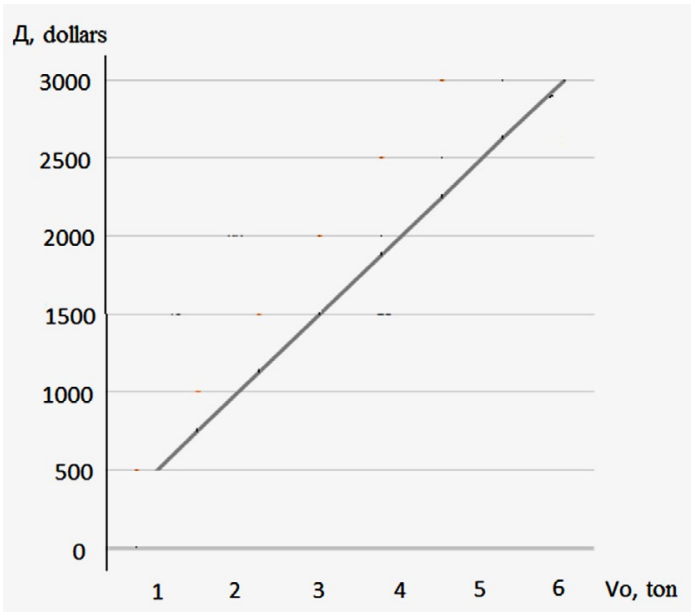

Fig. 7. Dependence of income growth on the volume of generated waste raw materials

Table 1. Comparative data on degreasing with de-limonene and without de-limonene

\begin{tabular}{ccc}
\hline Method degreasing & $\begin{array}{c}\text { Fat content of fat-free } \\
\text { fish raw materials }\end{array}$ & $\begin{array}{c}\text { Fat content of lean } \\
\text { fish bones }\end{array}$
\end{tabular}

\begin{tabular}{lll}
\hline Degreasing with de-limonene & $4 \%$ & $5 \%$ \\
Degreasing without de limonene & $5 \%$ & $6 \%$
\end{tabular}


including the intensity of phase movement. It is natural that the given internal phenomena are the result of joint contact of the processing object with an external energy source and the environment, which is displayed in the structural diagrams (IV) and (V) of the hierarchy levels of the system analysis of the degreasing process of raw materials of animal origin.

Phenomena (IV) of the hierarchy level of the system analysis are presented in the structural diagram of physicochemical factors in Figure 4 and determine the occurrence of a boundary field (DOBF) over the object of processing, characterized by the fields of temperature distribution (FTD) and the speed of movement of objects in the cooking process (SMOCP).

The dynamic movement of the defatted raw material during cooking in water (DMPODCW) with the help of a rotating stirrer inside the digester is of direct importance to them.During continuous cooking of defatted raw materials, contact surfaces (CS) appear on account of the interaction with a high-temperature flow (IHTF). The dynamic movement of the raw material to be degreased causes a widespread conjugation with a stream of high temperatures, thus forming a redistribution of the temperature, humidity, and fat fields in the raw material particles in the working area of the degreasing device. Additionally, the runway above the object of degreasing is influenced by the effects (III) of the hierarchy level of the system analysis, in terms of the operation of the degreasing device.

Intensive circulation and thermoregulation by adjusting the temperatures in the device as well as supply and influence of additional fat absorbers in the working environment of cooking leads to an intensification of the process of defatting raw materials of animal origin.

The main parameter (V) characterizes the level of the hierarchy of the system analysis of the process of defatting raw materials of animal origin, the structural diagram of which is presented in Figure 5. This includes the structural elements of the defatting device (SEDD), which additionally allow the fat absorbers to interact during the thermal cooking process. Here, the following should be understood: the work of mechanical treatment (WMT) required for mixing (M); the work spent on heating the coolant (WSHC) entering the device for degreasing; work required to transfer heat over the volume of the degreasing device (WRTHOVDD); thermal disturbances brought with the inlet flows of the coolant, and the dynamic movement of the degreasing object (TDBFCDMDO). These phenomena bring heat and mass flows in the internal volume of the degreasing device, which form the fields of heat and mass transfer (FHMT) as well as moisture transfer (FMT) inside the degreasing device. High-temperature currents in the device for degreasing and the mass of additional fat absorbers (HTCVDDMAFA) significantly affect the release of fat from raw materials during the operation of the device (SARFRMAODODD), its quality of degreasing and disinfection (QDWD), the time of heat treatment in the device for defatting (THTDD), and productivity of finished fat (PFF).

Based on the systematic analysis of the degreasing process of raw materials of animal origin, it was found that the main indicators which intensify degreasing are:

- The use of additional absorbers of fat in water during high-temperature cooking of raw materials of animal origin;

- Increasing the contact area between the degreased raw materials and the heat carrier;

- Application of the entire surface of the raw material to be degreased;

- An increase in the temperature of the coolant without compromising the quality of the fat.

In order to increase the productivity of skimming fish bone raw materials during hightemperature cooking of fish bone raw materials into the water, where the cooking was carried out, an additional fat absorber, de-limonene, was added. De-limonene is the main component of orange peel oil and is a widespread terpene hydrocarbon. It is also found in almost all citrus fruits and many other essential oils such as of lemon, tangerine, lime, grapefruit, bergamot, neroli, petitgrain, elemi, cumin, dill, fennel, parsley, and Erigeron and Orthodon species.

Figure 6 shows the time dependence of defatting using de-limonene and without using de-limonene. Figure 6 shows that the performance of degreasing using de-limonene is increased as compared to when de-limonene is not used. Fat extraction using de-limonene increases the degree of collagen hydrolysis of animal raw materials, 
which ultimately intensifies the extraction of fat from raw materials. High temperature mode breaks down triglycerides into free fatty acids, which entails degradation into low molecular volume products.

Table 1 shows that the inclusion of delimonene in the defatting process during cooking is conducive to the extraction of fat from cooked raw materials. The fat contained in fish and bone raw materials melts during cooking and turns liquid. The amount of fat entering the cooking medium also depends on its content and the nature of its deposition in the product, the duration of cooking, and the size of the pieces.

The most important thing in the algorithm for calculating the technical and economic efficiency of processing raw materials of animal origin into valuable fat is that the costs of raw materials are not taken into account, because they are often waste (often bone in the form of food residues, scales, fins, and fish heads that are leftovers from cutting fish and not used in food) and are therefore free of cost. Figure 7 shows the dependence of income growth on the volume of the generated waste raw materials.

Thus, the defatting of raw materials of animal origin makes it possible to obtain a sufficiently high economic effect with the production of healthy fat.

\section{CONCLUSION}

It has been established that thermal defatting is a necessary process in the production of fat and feed. The method of system analysis revealed the main characteristics which could improve the technology used in defatting raw materials of animal origin for the production of fat, namely, the use of an additional fat absorber (de-limonene) in water during the process of hightemperature cooking of raw materials $(\mathrm{m})$ and focus on cooking temperature of raw materials of animal origin ( $\mathrm{T}$ ) as well as duration of cooking of raw materials of animal origin ( $t$ ). A new method of defatting with the use of digesters and the inclusion of an additional fat absorber during cooking (de-limonene) was developed.

\section{CONFLICT OF INTEREST}

The authors declare that there is no conflict of interest.

\section{AUTHORS' CONTRIBUTION}

All authors listed have made a substantial, direct and intellectual contribution to the work, and approved it for publication.

\section{FUNDING}

None.

\section{DATA AVAILABILITY}

All datasets generated or analyzed during this study are included in the manuscript.

\section{ETHICS STATEMENT}

Not applicable.

\section{REFERENCES}

1. Iskakov RM, Iskakova AM, Issenov SS, Beisebekova DM and Khaimuldinova AK. Technology of Multi-stage Sterilization of Raw Materials With the Production of Feed Meal of High Biological Value. Journal of Pure and Applied Microbiology, 2019;13(1):307-312. doi:10.22207/JPAM.13.1.33

2. Chandra S., Stanford D., Fletcher E., Walker L.A. (2019) Raw Materials Production and Manufacturing Process Control Strategies. In: Sasisekharan R., Lee S., Rosenberg A., Walker L. (eds) The Science and Regulations of Naturally Derived Complex Drugs. AAPS Advances in the Pharmaceutical Sciences Series, 32. Springer, Cham. doi: 10.1007/978-3-030-11751-1_10 3. Iskakova AM, Abzalova RA and Beisebekova DM. Analysis of Medical and Social Technologies in Nursing at the Level of Primary Health Care. Biology and Medicine, 2015;7(4):5.

4. Iskakova AM, Abzalova RA, Shalgumbaieva GM et al. The Implementation of New Nursing Technologies in the Republic of Kazakhstan. Problemy sotsialnoi gigieny, zdravookhraneniia i istorii meditsiny, 2016;24(3):182-185.

5. Iskakov RM, Issenov SS, Iskakova AM, Halam S and Beisebekova DM. Microbiological Appraisal of Feed Meal of Animal Origin, Produced by Drying and Grinding Installation. Journal of Pure and Applied Microbiology, 2015;9(1), 587-592.

6. Tlebayev MB, Biibosunov BI, Taszhurekova ZhK, Baizharikova MA and Aitbayeva ZK. Creation of a Computer-Assisted Mathematical Model for the Raw Materials Biological Processing. Periodico Tche Quimica, 2020;17(35):640-654A.

7. Kiss AA, Grievink J and Rito-Palomares M. A Systems Engineering Perspective on Process Integration in Industrial Biotechnology. Journal of Chemical Technology and Biotechnology, 2015 ;90(3), 349-355. doi: $10.1002 /$ jctb. 4584

\section{ACKNOWLEDGMENTS}

None. 
8. Kudrin MR, Krasnova OA, Koshchaev AG, et al. Biological Processing of Renewable Raw Materials Resources With Regard to the Environmental and Technological Criteria. Journal of Ecological Engineering, 2019;20(11), 58-66. doi: 10.12911/22998993/113192

9. Zagorulko A, Zahorulko A, Kasabova K, et al. Universal multifunctional device for heat and mass exchange processes during organic raw material processing. Eastern-European Journal of Enterprise Technologies,2018;6(1-96):47-54. doi: 10.15587/17294061.2018.148443
10.

Iskakov RM, Issenov SS, Iskakova AM, Halam S and Beisebekova DM. Heat-and-Moisture Transfer at the Feed Meal Particles Drying and Grinding. Life Science Journal, 2013;10(12s);497-502.

11. Golovin AN, Methods for determination of fat (lipid) content Control of fish production. (in Russian). - M.: Pishchevaya promyshlennost', 1978;pp: 105.

12. Iskakov RM and Smailova AK. Utility model patent No. 4850 KZ. Method for the Production of Fat and Feed Meal from Waste Bone Raw Materials of Farm Animals and a Line for its Implementation. A23N17/00, A23K1/10. Publ., 10.04.2020. 